\title{
A memória da Comunicação em instituições biomédicas: considerações sobre os efeitos da comunicação organizacional em mudanças na relação biomédico-paciente
}

\author{
Simone Vaisman Muniz
}

\section{Resumo:}

Um dos efeitos que vêm surgindo na sociedade contemporânea atribuído à Comunicação Institucional - ainda que não apenas a ela - é uma transformação no modo como as pessoas consideram as fontes oficiais de informação da Biomedicina. A Comunicação Institucional em sua história produziu enunciados em relação à realidade social que parecem hoje impor um modelo hegemônico de cognição às atividades de pesquisa, de produção de políticas da biomedicina e também no dia-a-dia do relacionamento entre biomédico e paciente. Qual a relação entre esses efeitos de tematização do cotidiano biomédico pela Comunicação Institucional e as condições sociais e históricas que permitiram a emergência dessa área como a instância que transforma os acontecimentos da Biomedicina e os eleva à condição de socialmente importantes?

\section{Palavras Chave:}

comunicação institucional, saúde, memória social.

\begin{abstract}
:
One of the effects attributed to Organizational Communication - although not only to it - that appears on contemporary societies is a transformation in the way people consider Biomedicine official information fonts. The Organizational Communication in its history produced statements in relation to social reality that seems to impose today an hegemonic model of cognition to biomedical research activities, biomedical political production activities and also at day-by-day relationship between biomedical and patient. What is the relationship between these efects of the tematization made by biomedical institucional and the social and historical conditions that allowed the emergency of Organizational Communication as an instance that disturbs dayly Biomedicine events and raises them to the condition of socially important?
\end{abstract}

\section{Keywords:}

organizational communication, health, social memory.

\section{O lugar de gerenciamento das informações institucionais}

A Comunicação Institucional se torna cada vez mais uma instância indispensável no trabalho de mediação das informações entre organização e sociedade. Ela é geralmente um departamento da organização - ou, às vezes, um serviço terceirizado - que importa dos profissionais da mídia como jornalistas, relações públicas, publicitários e outros especialistas da indústria cultural grande parte dos seus saberes. O departamento se propõe a esclarecer e estimular a participação da sociedade nas ações da organização, por meio de materiais e eventos distribuídos para as várias pessoas que interagem direta ou indiretamente no dia-a-dia da organização, como os consumidores dos produtos e serviços, funcionários da casa, os profissionais da mídia. A Comunicação Institucional se insere como o lugar em que se pensa, transforma e mantém a imagem das instituições. 
Este lugar de planejamento e organização das informações da instituição e do relacionamento delas com o público vêm ganhando um papel fundamental na sociedade contemporânea e, junto com ele, também aumentam os efeitos nos vários públicos com que dialoga. A Comunicação Institucional têm o poder de inclusão de certos assuntos nas práticas rotineiras dos mais diversos consumidores da informação. Ela direciona, de certa maneira, a memória dos indivíduos sobre os acontecimentos da instituição e também sobre o papel da instituição, sua relevância, seus valores, sua história. Assumimos que existe por parte dos indivíduos uma certa dependência cognitiva da Comunicação Institucional na seleção e enquadramento dos acontecimentos que fazem parte do dia-a-dia da organização. Um exemplo disso está na emergência do tema "promoção da saúde" ou "envelhecimento saudável" nos últimos anos junto com o crescimento da Comunicação Institucional nas empresas de saúde.

Segundo Debert (1999), o envelhecimento se transforma num problema que ganha expressão e legitimidade no campo das preocupações sociais, principalmente a partir dos anos 1970. O debate sobre o envelhecer no Brasil resultou na implementação de uma Política Nacional da Saúde do Idoso e na constituição de uma Rede Nacional de Proteção e Defesa da Pessoa Idosa. (...)

A quantidade de pesquisas e de produtos culturais sobre o "envelhecimento saudável" se multiplica no campo da saúde, movimento o qual Debert chamou de 'reinvenção da velhice". Se há três décadas, praticamente não se falava no assunto nos meios científicos, entre outras instituições centrais da modernidade, atualmente, a preocupação com as formas de envelhecer e com as pessoas de idade avançada se torna cada vez mais central. E caminha junto com outras transformações, sobretudo na racionalidade da sociedade contemporânea, nos saberes técnico-científicos (MUNIZ, 2007: 20-21).

A orientação da promoção do "envelhecimento saudável" como uma temática presente no cotidiano da sociedade contemporânea só pode emergir graças a certas condições sociais e históricas. Dentre elas, está a profissionalização das informações nas organizações segundo os critérios dessa área chamada Comunicação Institucional. Existe uma correlação entre o fortalecimento dessa área e a inserção dessa temática na agenda da mídia e da sociedade nos últimos anos.

A Comunicação Institucional projeta acontecimentos que, por experiência ou por tabela, se relacionam com os saberes do dia-a-dia dos consumidores da informação. Não se quer dizer que a Comunicação Institucional, ao mesmo tempo em que se firmou, conseguiu induzir, provocar e convencer as pessoas de quais temas eram importantes. Simplesmente não se pode negar que as categorias que a Comunicação Institucional fornece ajudam os destinatários a organizarem os temas, ainda que seja bastante difícil precisar o modo como cada indivíduo o faz. Nesse sentido, os estudos sobre Comunicação Institucional se assemelham ao que Wolf (2006) chama de "hipótese do agenda setting", ou seja, promovem sobre os indivíduos efeitos a longo prazo.

Um dos efeitos que vêm surgindo na sociedade contemporânea atribuído à Comunicação Institucional - ainda que não apenas a ela - é uma transformação no modo como as pessoas consideram as fontes oficiais de informação da saúde. No caso da Biomedicina, as fontes de informação com base bibliográfica, que sempre se apresentaram como os lugares legitimados e autorizados para as intervenções na área, parecem estar perdendo esse papel para outros órgãos de informação e cultura, especialmente, os relacionados às organizações contemporâneas. A Comunicação Institucional produz enunciados em relação à realidade social e parece ganhar o estatuto de porta-voz de verdades. Organizações que não fazem parte do mundo bibliográfico autorizado da Saúde disputam o papel de formalizador das informações em saúde com as organizações tradicionais de pesquisa e de elaboração de políticas na área. O discurso das fontes ditas "não-oficiais" acaba por impor às atividades de pesquisa e de produção de políticas da saúde um modelo hegemônico de cognição sobre a Saúde. Por isso, as informações atribuídas à Comunicação Institucional têm sido cada vez mais utilizadas em atividades ligadas à elaboração de pesquisas e comunicações em bases bibliográficas em saúde 
e também no dia-a-dia do relacionamento entre biomédico e paciente (MUNIZ, 2007).

Até pouco tempo, os profissionais da Biomedicina ou aceitavam de forma a-crítica as informações da saúde provenientes de fontes não-oficiais como o conhecimento científico ou a legislação ou as rejeitavam plenamente. Hoje, parece haver uma transformação relacionada às informações em saúde. Para Castegnau (BIREME, 2006), se antes a pesquisa estava calcada sobretudo em bases bibliográficas já legitimadas e expressivas, hoje também emerge um conjunto de mudanças que parece abrir o universo das representações sociais aceitas pelo consenso da sociedade e também reconhecer a presença de outras fontes de informação. $\mathrm{O}$ verdadeiro agora não se encontra mais apenas calcado no discurso das bases bibliográficas formais.

Qualquer informação é passível de se tornar fonte de biomedicina porque se assume que a responsabilidade pela seleção e o enquadramento das informações em saúde para o indivíduo é uma responsabilidade coletiva, e não mais restrita a grupos sociais como os biomédicos. Admite-se que as informações em saúde são uma construção social não só dos profissionais da área e que há a necessidade de colaboração de outros grupos sociais. Isso abre espaço para novas especializações e para o trabalho interdisciplinar. E, sobretudo, nos permite investigar melhor a hipótese deste trabalho. Nessas mudanças, a Comunicação Institucional emerge como um saber fundamental. A emergência das idéias de autonomia da área de promoção dos acontecimentos relacionados a uma empresa representa um compromisso com o social, a partir da mediação entre os saberes especializados e o mundo da vida. Os efeitos de sentido que a Comunicação Institucional constrói projetam o relacionamento entre biomédico e paciente como um trabalho que exige da Comunicação Institucional o gerenciamento e promoção dos acontecimentos sobre a Biomedicina. Nos produtos da área, o biomédico e o paciente são inseridos como agentes conscientes e exigentes do trabalho dela.

A Comunicação Institucional, assim, se posiciona como um novo tipo de organização e funcionamento da cultura, que associa o consumo de certos tipos de informação a agentes autônomos e certos das escolhas de estilos de vida. Mas essas escolhas, na verdade, são o que ela acredita representar as demandas desses públicos. Ela cria efeitos de interesse e expectativas e enquadra os consumidores em responsáveis por uma parte do todo social, a parte que eles consomem. Isso é feito segundo certos critérios de seleção e produção da informação, certos padrões, exigências e rotinas produtivas.

A Comunicação Institucional da empresa Unimed retrata bem essa relação de semelhança. A empresa de planos de saúde tem como foco da Comunicação Institucional a temática da promoção da saúde e disponibiliza no seu site informações e pesquisas sobre a prevenção, por meio de assessoria de imprensa ou de fontes profissionais. A Unimed não é a única. Como ela, outras empresas relacionam alguns acontecimentos e os fazem emergir como interesse dos médicos e dos pacientes, conjuntamente. Assim, no site da Unimed, são divulgados, sob a forma de releases ou de reportagens, informações sobre concursos, projetos, cursos, e dicas de saúde como "como controlar o mau-hálito". As categorias são "qualidade de vida" - dentro dela, "nutrição", "prevenção e bem-estar", "primeiros socorros" -, "doenças", "notícias de saúde", "testes e tabelas", entre outros, como em uma revista eletrônica sobre saúde. A seleção e o enquadramento desses acontecimentos como dignos de serem associados a outras informações sobre a empresa estão em consonância com os efeitos que a Comunicação Institucional deseja provocar na sociedade. São efeitos os de se inserir como um lugar legítimo de transparência e responsabilidade, de publicização e gerenciamento da informação relacionada à instituição para a sociedade.

O slogan da Unimed veiculado na mídia "o melhor plano de saúde é viver, o segundo melhor é a Unimed" mostra como se produz a saúde segundo um novo modo de organização da cultura (RUBIM, 1998). A Comunicação Institucional enfatiza a si própria como o lugar de mobilização das temáticas que supostamente são de interesse consciente dos públicos ligados à organização, promovendo as ações da instituição à condição de demandas e expectativas dos consumidores. Assim, a "qualidade de vida", como a promoção da saúde e os vários acontecimentos ligados a ela não indicam meramente valores que a organização gostaria de 
assumir para si. Eles mostram o modo como a Comunicação da organização trabalha, consciente e inconscientemente, junto aos discursos da Biomedicina - antes o principal lugar social de produção de informações legitimadas - em apropriações e disputas pela produção da memória social sobre a área em que a atua, a saúde.

Em trabalho anterior (MUNIZ, 2007), analisamos essa relação entre a emergência da temática da "promoção do envelhecimento saudável", a transformação das fontes confiáveis na biomedicina e do relacionamento entre biomédico e paciente e a produção dessas informações pela área de Comunicação de empresas e sociedades médicas que lidam com os temas dos medicamentos sobre osteoporose, doença de Alzheimer, entre outros ligados à idade avançada. Os informativos sobre o papel do geriatra, a vacinação na terceira idade e a prevenção do câncer de próstata também são provas de que hoje a terceira idade se firmou como uma temática importante no imaginário dos consumidores das informações. Ainda que não haja evidências que mostrem o tamanho da responsabilidade da Comunicação Institucional nessa naturalização do "envelhecimento saudável" nas sociedades contemporâneas. Não buscamos medir esse papel da Comunicação, mas mostramos que a "terceira idade" e a preocupação com o envelhecer de modo saudável nem sempre foram assuntos tão presentes como hoje são na memória da sociedade.

O caso que mais chamou a atenção foi a campanha da Comunicação Institucional sobre um medicamento contra disfunção erétil. Embora não se possa medir os efeitos da presença desse tema na sociedade nem o tamanho da influência do que se fala sobre o assunto, é evidente que em poucos anos ele passou a ocupar uma posição relevante na mídia, na Comunicação Institucional e em outras instituições sociais. Hoje, os conhecimentos sobre a questão já fazem parte da enciclopédia dos destinatários. O modo como os médicos e pacientes passaram a tratar da disfunção erétil, reforçando a mudança de status do função sexual na terceira idade de um problema da intimidade dos casais para uma questão de saúde pública mostra como a Comunicação Institucional desempenha uma papel importante na tematização dos assuntos de interesse público na sociedade.

\section{As projeções da Comunicação Institucional}

É importante investigar as condições de possibilidade desses discursos do profissional da Comunicação como mediador das informações que se tornam legítimas e se efetuam como parte do interesse de todos. E, sobretudo, analisar a história de como os critérios, as exigências e a cultura da área se tornam naturalizados e universalizados.

A Comunicação Institucional se torna um saber cada vez mais imprescindível na produção de sentidos que orientam a maneira como a organização produz sua memória. Existe uma relação entre a profissionalização da Comunicação como lugar de mobilização da sociedade e de compromisso com o social e as mudanças no estatuto da biomedicina, com a emergência da "promoção da saúde" como tema presente na agenda dos indivíduos. Ela influencia na orientação dos modos de agir, investindo a saúde como uma parte de certos estilos de vida, jeitos de viver. A idéia de gerenciamento e publicidade das informações como um novo modo de organização e funcionamento da cultura, produzida pela Comunicação Institucional, se encadeia com a forma como ela eleva os acontecimentos da saúde à categoria de interesses e demandas sociais. Um dos objetivos de se compreender essa relação é desmistificar a idéia de que todos entendem como funciona o trabalho de produção de sentidos da Comunicação Institucional. Ela não é algo natural e universal para todos. Muitas vezes esse modo próprio de realizar as escolhas dos acontecimentos relevantes para a organização só é compreendido pelos próprios profissionais de Comunicação. Por isso, são importantes os estudos que ajudem a desnaturalizar os critérios e as exigências de administração e promoção das informações realizadas pela Comunicação Institucional nas instituições de saúde.

A Comunicação Institucional, ao produzir sentidos sobre a necessidade de um espaço autônomo para a 
produção dos acontecimentos dentro da organização - a necessidade de si mesma -, se projeta sobre a área da Biomedicina e ajuda a construir este campo segundo certas qualidades de entendimento. É claro que esse trabalho da Comunicação Institucional sobre a Biomedicina e a resposta desta última não são autônomos nem auto-referenciados, e que existem referentes materiais, dimensões subjetivas, ideológicas e sociais, associadas às temáticas da promoção da saúde e do envelhecimento saudável que contribuem para o fazer emergir social e historicamente como temática importante ou não. Não negamos aspectos biológicos, psíquicos e sociais, como as alterações nas representações de gênero, o envelhecimento populacional, entre outros inúmeros, que influenciam a emergência de formas de representação do avanço da idade em espaços sociais da contemporaneidade.

Mesmo considerando esses aspectos, temos exemplos de como a Comunicação produz as demandas e expectativas dos públicos diferenciados. A emergência do tema do bem-estar e da intimidade dos casais na terceira idade como um acontecimento da Biomedicina é um deles. E essa projeção da Comunicação Institucional não é de hoje. Ela foi sendo construída ao longo dos anos segundo critérios importados de outras áreas. Mas, apesar dessa dependência de outros saberes, a Comunicação Institucional vem se constituindo cada vez mais um campo de conhecimento autônomo e automotivado, estimulado por rotinas e pela troca com outros colegas do mesmo ramo, pelas agregações e comparações entre os grupos de referência na mesma área. Esse movimento está inserido na necessidade de ela se firmar como lugar autorizado para produzir informações na sociedade. Dessa forma, as técnicas, os conjuntos de regras, normas próprias, pressões e condições das rotinas produtivas e a cultura profissional dotam a Comunicação Institucional de um efeito cada vez maior de autonomia e automotivação.

Mas os efeitos de sentido, ao mesmo tempo em que atribuem à Comunicação Institucional um status de instância autônoma de produção, também sofrem interferência e pressão de outras variáveis, fatores ligados a outros saberes, rotinas e práticas presentes na memória dos indivíduos. As campanhas publicitárias, os sites, as matérias, os estudos de caso e outros produtos e resultados do trabalho da Comunicação Institucional mostram a tensão entre a autonomia da área e a dependência externa. Os acontecimentos sobre saúde presentes na agenda da Comunicação nas instituições da área mostram que, na produção de si mesma como um novo modo de funcionamento da cultura e como "mobilização", a Comunicação Institucional também precisa se relacionar com o Outro, com os outros saberes.

Existe uma relação entre a produção dos acontecimentos da Biomedicina pela Comunicação Institucional e a maneira como esta última produz a si mesma. É importante, para os futuros estudos na área, demonstrar que é falsa a idéia de que se os comunicadores pudessem se libertar dos vínculos com as autoridades - sejam ela a direção da empresa ou os saberes biomédicos especializados, por exemplo -, a autonomia profissional garantiria imparcialidade, tal como sugeriu Wolf (2006) a respeito do trabalho dos jornalistas. E ainda, no caso da Comunicação nas organizações, asseguraria o compromisso com o social e o perfeito gerenciamento e publicidade da informação. Ser autônomo não significa estar livre do jogo de forças. A imparcialidade e a responsabilidade social atribuídas à Comunicação Institucional são mitos ligados não ao desligamento dos vínculos, não apenas às relações internas com a instituição, mas a complexas relações de força, que nos propomos a esclarecer por meio dos instrumentais teórico-metodológicos do fenômeno da Memória Social.

\section{Considerações finais}

Como pesquisar a relação de longo prazo entre esses efeitos de tematização e as condições sociais e históricas que permitiram a emergência da Comunicação Institucional como a instância que eleva os acontecimentos da promoção da saúde à condição de socialmente importantes? As pesquisas sobre Memória Social constituem um dos principais referenciais teórico-metodológico que observamos no trabalho de Enne (2001), Barbosa (1998), Ribeiro (1995) e de Pollak (1992 e 1998). Elas tratam das relações de poder e de disputa existentes na produção da memória e de identidade e dos efeitos cognitivos nos indivíduos. Esses autores compreendem 
que as pesquisas em áreas em que há interdisciplinaridade na Comunicação esbarram com problemas teóricometodológicos que devem ser pensados durante a elaboração das pesquisas.

Um dos problemas revelados pela interdisciplinaridade especificamente no tema da Comunicação Institucional é que as diferentes profissões, saberes e formações interferem de maneiras distintas nas condições de interpretação dos produtos. Se especificarmos as rotinas de produção, diferenciando os níveis do processo de aquisição das informações, percebemos que os dados obtidos revelam papéis diferentes para os vários profissionais e produtos da gerência da Comunicação Institucional. E mesmo os especificando papéis diferentes para cada profissional - publicitário, relações públicas, jornalista - e para tipo de produto - um filme, uma peça, uma reportagem, uma publicação têm rotinas de produção diferentes -, deparamo-nos com a falta de homogeneidade entre as leituras dos diferentes tipos de produtos da Comunicação Institucional. Produtos heterogêneos têm efeitos diferentes sobre os públicos quantitativa e qualitativamente diferenciados, como lembrou Wolf (2006).

Uma das soluções possíveis é trabalhar temáticas. Daí a escolha da "Biomedicina" e, mais especificamente, das mudanças nela, sobretudo, da emergência da "promoção da saúde", como objeto deste trabalho. Quando se relaciona os "tipos de informação" difundidas e passadas de uma agenda de tematização para outra - da área da Biomedicina para a Comunicação Institucional - se consegue observar melhor os efeitos que uma exerce sobre a outra, pois se percebe a complexidade das apropriações e disputas pela elevação das representações sociais ao estatuto de interesse (consciente ou inconsciente) coletivo, à memória social.

Os autores que trabalham com as temáticas da memória social e da identidade relacionada à Comunicação respondem que as representações coletivas são construções sociais, ideológicas e subjetivas, ligadas aos lugares sociais nos quais estão inseridos os agentes das práticas de produção. A memória social funciona e se constitui como instrumento de poder, no qual se busca modificar ou impôr as disposições já existentes. Na disputa entre Comunicação Institucional e Biomedicina, a primeira, por ser cada vez mais aceita socialmente como fonte de promoção dos acontecimentos em saúde, impõe uma representação coletiva das entidades e fatos ligados a Biomedicina. Esta não é mais percebida como uma instituição segura.

Pollak pressupõe que existem duas formas de estruturação da memória coletiva - a memória hegemônica e a subterrânea. Os limites entre as memórias coletivas oficiais e subterrâneas são difíceis de traçar, pois as duas formas de estruturação da memória estão relacionados a disputas sociais. Eles têm a ver com a posição social e histórica nas práticas de produção e leitura dos produtos culturais de maneira variada em diferentes épocas e situações. Para o campo de estudos do fenômeno da memória social, as representações sociais ligadas à Biomedicina e à Comunicação Institucional são extremamentes maleáveis. Isso não significa estar distante da realidade mas acreditar que, nas apropriações das representações coletivas nos processos de produção e de leitura dos suportes da cultura, estão embutidos aspectos sociais, subjetivos e ideológicos de luta e de conformação.

Em trabalho anterior (Muniz, 2007), interpretamos a Comunicação Institucional junto aos profissionais que já trabalharam ou trabalham nela hoje em algumas das empresas que se promovem como ligadas à saúde ou bem-estar e que têm um histórico de fortes investimentos na área. Hoje, podemos destacar algumas como Pfizer, Unimed, Unilever, Amil, Natura, Aventis Farma, Merck. Por meio da análise de discurso de produtos de algumas dessas instituições, buscamos a relação entre a produção de identidades do comunicador, do biomédico e do paciente, no trabalho de produção de acontecimentos sobre promoção da saúde pela Comunicação Institucional. Entendemos os produtos da Comunicação Institucional na Biomedicina como vetores de socialização entre as duas categorias profissionais e também o usuário dos direitos e serviços por eles oferecidos.

Compreendemos que a administração e a publicização das ações ligadas à organização são as duas principais 
exigências do trabalho da Comunicação Institucional. E que a Comunicação Institucional oscila entre colocar o interesse da organização e o interesse do público acima de tudo (recorrendo às questões da intimidade com o produtor ou o consumidor) ou reforçar a idéia de autonomia com base nas técnicas e tecnologias. Nesse movimento pendular, os profissionais da Comunicação Institucional apagam a si mesmos e constróem novas representações do relacionamento entre biomédico e paciente, baseadas sobretudo, no apelo à categorias do mundo da vida, os quais são usadas para ilustrar representações do "eu". Em futuros estudos, desejamos ouvir os profissionais e investigar as representações de "Comunicação Institucional" e "Biomedicina" e de "públicos" e de "interesse coletivo". Em que contextos aparecem e como são encadeados esses discursos? Como o relacionamento entre essas representações e a maneira de produzi-las e interpretá-las na Memória Social se transforma ao longo dos anos? Essas questões ajudarão a responder como a Comunicação Institucional constrói sua história em relação a outras instâncias sociais.

\section{Bibliografia:}

BARBOSA, Marialva. Memória e tempo: arcabouços do sentido da contemporaneidade. Ciberlegenda, v. 1, 1998.

BARROS, Myriam Lins de (org.). Velhice ou terceira idade? Estudos antropológicos sobre identidade, memória e política. Rio de Janeiro: Editora FGV, 2003.

DEBERT, Guita. A reinvenção da velhice: socialização e processos de reprivatização do envelhecimento. São Paulo: Edusp, 1999.

ENNE, Ana Lucia da Silva. Memória e identidade social. In: XXIV Congresso Brasileiro de Ciências da Comunicação (Intercom), $2001 . \quad$ Anais. reposcom.portcom.intercom.org.br/bitstream/1904/4357/1/NP2ENNE.pdf. Acessado em: 2008.

HALL, Stuart. A identidade cultural na pós-modernidade. Rio de Janeiro: DP\&A, 2004.

MUNIZ, Simone Vaisman. Memória Social e Promoção do Envelhecimento Saudável: a Comunicação Institucional como registro de um novo tipo de mobilização. Orientador: Nilson Alves de Moraes. Rio de Janeiro: Programa de Pós-Graduação em Memória Social, UniRio, 2007.

NASSAR, Paulo; FIGUEIREDO, Rubens. O que é a comunicação empresarial. São Paulo: Brasiliense, 1995 (Primeiros Passos, 297).

NORA, Pierre. Entre memória e história: a problemática dos lugares. Projeto História: Revista do Programa de Estudos Pós-Graduados em História e do Departamento de História. São Paulo, v. 10, p. 7-28, 1993.

POLLAK, Michael. Memória e identidade social. Estudos Históricos. Rio de Janeiro, v. 10, p. 200-215, 1992. . Memória, esquecimento, silêncio. Estudos Históricos. Rio de Janeiro, v. 10, p. 3-15, 1988.

REGO, Francisco G. T. Comunicação empresarial, comunicação institucional: conceitos, estratégias, sistemas, estrutura, planejamento e técnicas. São Paulo: Summus, 1986.

RIBEIRO, Ana P. G. A História do seu tempo: a imprensa e a produção do sentido histórico. Dissertação (Mestrado em Comunicação Social) - Escola de Comunicação, Universidade Federal do Rio de Janeiro, Rio de Janeiro, 1995.

RUBIM, Antonio A. C. Dos sentidos do marketing cultural. Revista Brasileira de Ciências da Comunicação, São Paulo, v. 21, n. 1, 1998, p. 141-149.

SILVA, Tomaz T. Identidade e diferença: a perspectiva dos estudos culturais. Petrópolis: Vozes, 2000.

WOLF, Mauro. Teorias da Comunicação. $9^{\mathrm{a}}$ ed. Lisboa: Editorial Presença, 2006.

\section{Mini Currículo :}

Jornalista, especialista em Comunicação e Saúde pela Fundação Oswaldo Cruz e mestre em Memória Social pela Universidade Federal do Estado do Rio de Janeiro (UniRio), atualmente trabalha no Ministério da Cultura (Funarte). E-mail: simonemuniz@ hotmail.com 


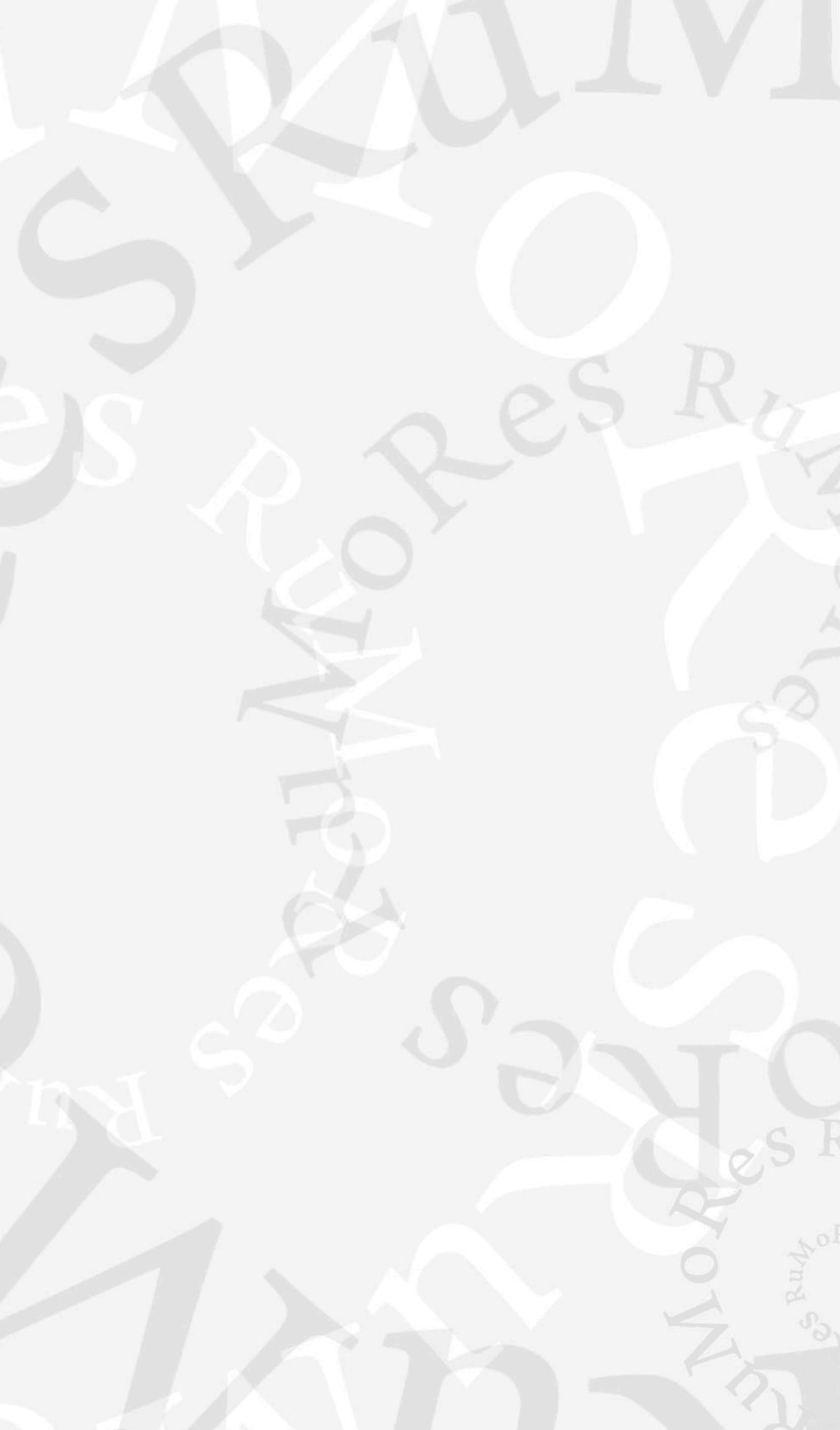

